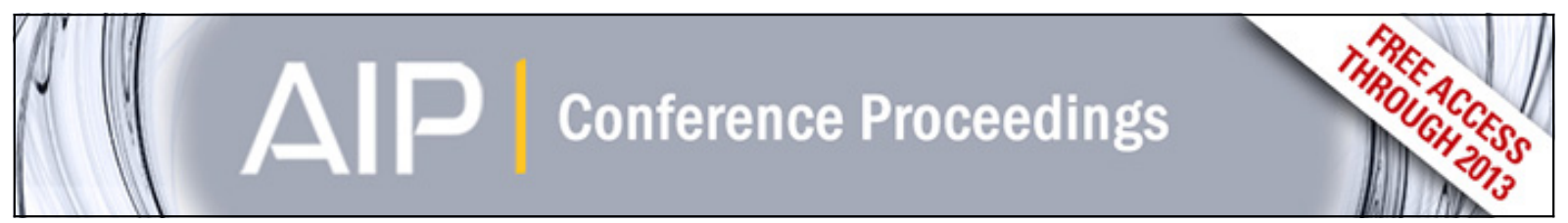

Investigation of crosslinking behaviour of silane grafted polyethylene through rheology

Ales Obr and Martin Zatloukal

Citation: AIP Conference Proceedings 1526, 230 (2013); doi: 10.1063/1.4802617

View online: http://dx.doi.org/10.1063/1.4802617

View Table of Contents: http://scitation.aip.org/content/aip/proceeding/aipcp/1526?ver=pdfcov

Published by the AIP Publishing 


\title{
Investigation of Crosslinking Behaviour of Silane Grafted Polyethylene through Rheology
}

\author{
Ales Obr ${ }^{\mathrm{a}}$ and Martin Zatloukal ${ }^{\mathrm{b}, \mathrm{c}}$ \\ ${ }^{a}$ SILON s.r.o, Planá nad Lužnicí, Prümyslová 451, Czech Republic \\ ${ }^{b}$ Polymer Centre, Faculty of Technology, Tomas Bata University in Zlin, \\ nam. T. G. Masaryka 275, 76272 Zlin, Czech Republic \\ ${ }^{c}$ Centre of Polymer Systems, University Institute, Tomas Bata University in Zlin, \\ Nad Ovcirnou 3685, 76001 Zlin, Czech Republic
}

\begin{abstract}
In this work the crosslinking behaviour of two silane-grafted polyethylenes was investigated with respect to time and temperature by using dynamic rheological measurements. It has been found that inhomogeneous character of the crosslinking reaction takes place in both tested samples. By utilization of $G^{\prime}-G$ ' crossover method, it has been found that the sample with initially distinct crosslinking state and short critical crosslinking reaction time has high tendency to create small gels during production of hot water pipes. It has also been revealed that the temperature dependence of the critical time, at which the crosslinking speed is the highest, shows an Arrhenius-type behaviour.
\end{abstract}

Keywords: Silane grafted polyethylene, Crosslinking behaviour, Gel point.

PACS: 83.60.Bc, 83.60.Df

\section{INTRODUCTION}

By crosslinking of polyethylene, many important properties can be drastically improved, which opens the space for new applications such as production of hot water pipes, heat shrinkable products in cable installation, heat-resistant food-stuff packaging (up to $200^{\circ} \mathrm{C}$ ), foams for thermal insulation, and chemical-resistant seals [1]. Crosslinking of polyethylene can be done through so called Sioplas process developed in 1968 [2] at which a mixture of silane and peroxide is added to molten polyethylene leading to silane grafting reaction by means of reactive extrusion. Silane grafting has some disadvantages namely long, geometry dependent reaction times due to the diffusion controlled mechanism of cross-linking; significant differences in the gel content and consequently in the product properties in case of minute changes in the formulation [3]. Moreover, there is a difficulty of uniform distribution of silane and thus there exists the probability of localized grafting and consequent formation of small gels [4]. Even if significant progress has been made in understanding of crosslinking reactions for silane-grafted polyethylenes [1-11], there is still free space for the research in this field to obtain knowledge, which could help to optimize the silane grafting process and processing conditions.

One of the very important property of croslinking materials is gel point, which represents the state at which penetrating network of crosslinked molecules is created for the first time and can be determined by rheological measurements in the dynamic-

Novel Trends in Rheology $V$

AIP Conf. Proc. 1526, 230-236 (2013); doi: 10.1063/1.4802617

(C) 2013 AIP Publishing LLC 978-0-7354-1151-7/\$30.00 
mechanical mode. At the gel point, the transition from the viscoelastic liquid to the viscoelastic solid takes place, which is characterized by the frequency independent loss factor $\tan \delta$ [12-13]. However, if the crosslinking reaction is not homogenous through the sample (due to initiation of the crosslinking reaction at the free surface for example), this well established rheological method for determination of physically well-defined gel point can fail [14-15]. In order to assess at least semi-quantitative information of the crosslinking behavior, so called gelation index, GI, was recently introduced [15]. GI is based on method described in [16-17] and it is defined as the time to reach intersection of $G$ ' and $G$ ', i.e. distinct crosslinking state of the sample.

In this work, crosslinking reactions of two slightly different silane-grafted polyethylenes were investigated through rheology in order to understand unwanted gel formation in hot water pipe production.

\section{EXPERIMENTAL}

\section{Material}

In this work, two slightly different silane cross-linkable polyethylenes prepared by Sioplast process were used. Sample 1 NOK has very high tendency to create small gels during production of hot water pipes (see Figure 1, left) whereas Sample 2 OK do not (see Figure 1, right).
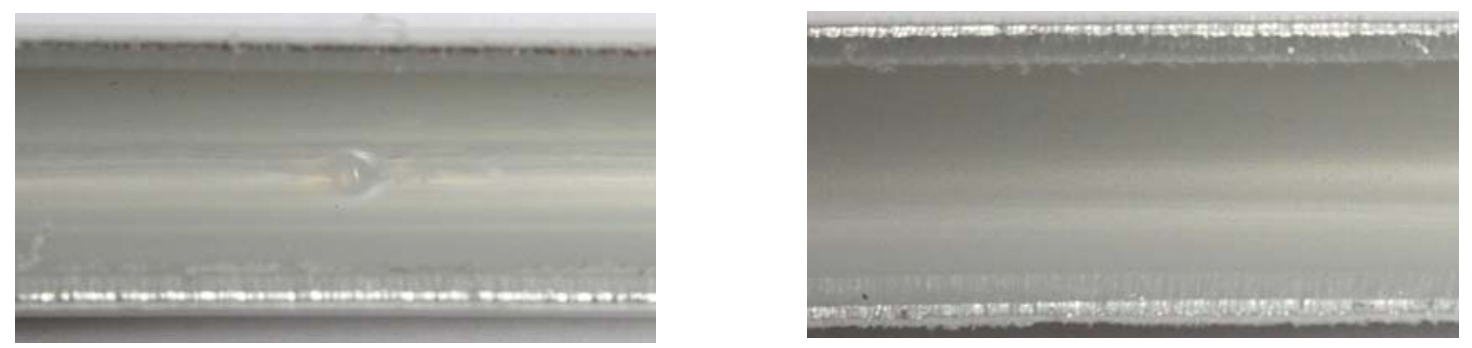

FIGURE 1. Examples of hot water pipe manufactured from NOK sample containing unwanted gels (left) and OK sample without gels (right).

\section{Rheological Measurements}

The rheological measurements were performed in an inert nitrogen and air atmosphere using a strain-controlled rheometer (ARES 2000, Rheometric Scientific) in the frequency sweep test (1-100 rad.s $\left.\mathrm{s}^{-1}\right)$ as well as in the time sweep test at constant frequency of 1 rad. $\mathrm{s}^{-1}$ utilizing a parallel plate geometry of $25 \mathrm{~mm}$. The temperature was varied between $205^{\circ} \mathrm{C}$ and $235^{\circ} \mathrm{C}$. 


\section{RESULTS AND DISCUSSION}

Basic rheological characteristics measured in nitrogen and air atmosphere for both investigated silane-grafted polyethylenes are summarized in Figures 2-5. Tan $\delta$ plotted versus the frequency for different crosslinking times show no horizontal line which would indicate a critical gel state. This can be explained by inhomogeneous character of the crosslinking reaction in both tested samples. Analysis of time dependent $G^{\prime}$ and $G$ ' moduli in Figures 2-5 (left side) reveals that NON sample has already passed $G$ ' $G$ ' crossover point whereas OK sample do not, which indicates more distinct crosslinking initial state for NOK sample in comparison with OK sample.
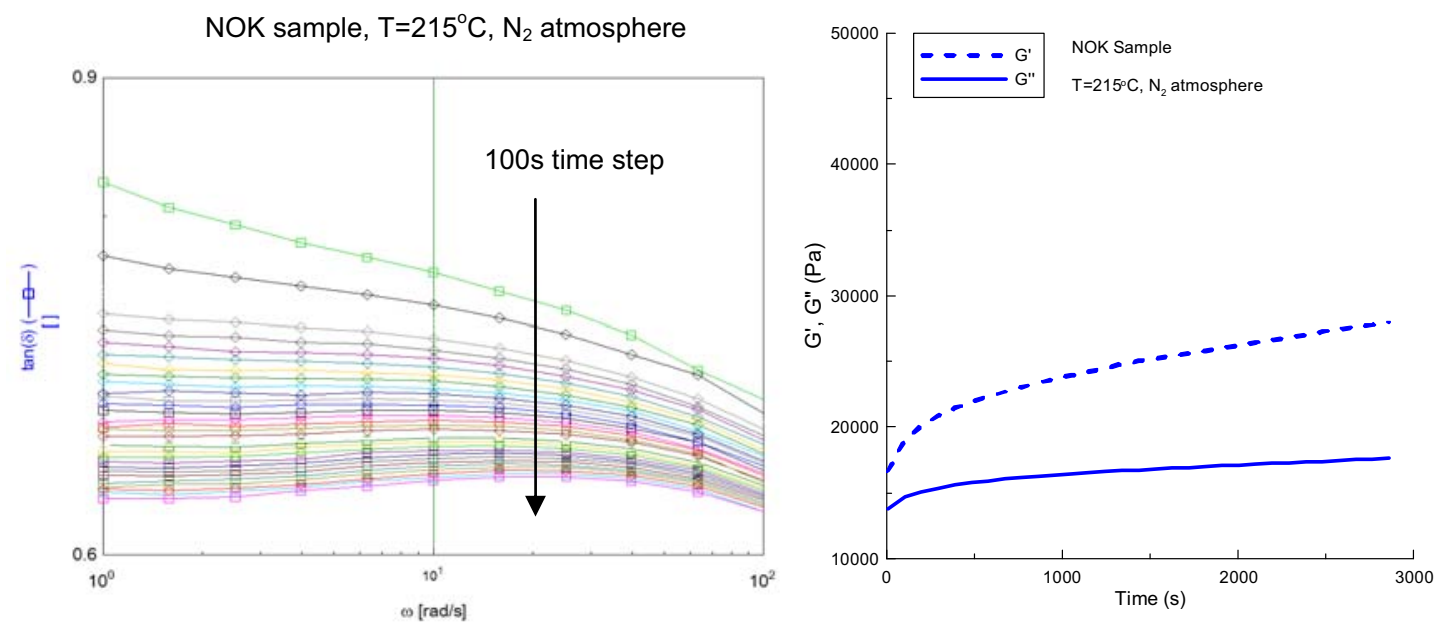

FIGURE 2. Rheological measurements for NOK sample at $215^{\circ} \mathrm{C}$ in nitrogen atmosphere.

Left: Plot of $\tan \delta$ versus the frequency for different crosslinking times (increased crosslinking time leads to the $\tan \delta$ decreases). Right: Loss and storage moduli versus the time.
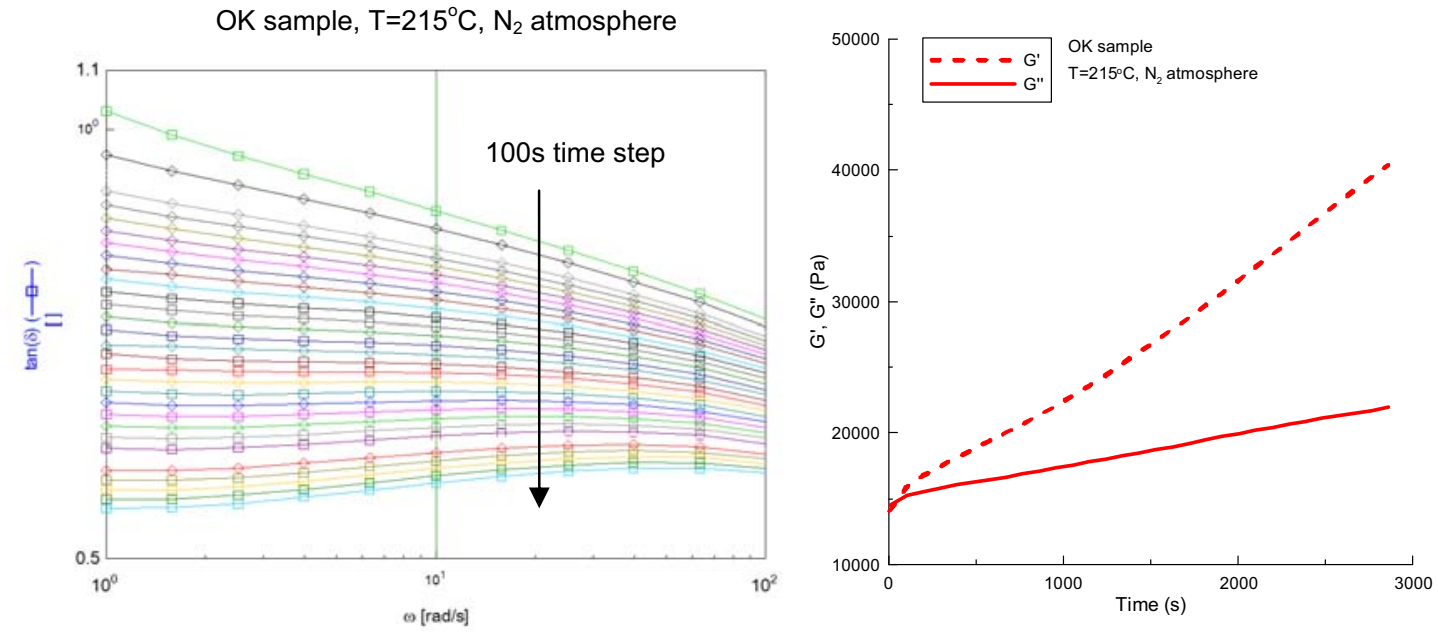

FIGURE 3. Rheological measurements for $\mathrm{OK}$ sample at $215^{\circ} \mathrm{C}$ in nitrogen atmosphere.

Left: Plot of $\tan \delta$ versus the frequency for different crosslinking times (increased crosslinking time leads to the $\tan \delta$ decreases). Right: Loss and storage moduli versus the time. 
On the other hand, utilization of recently proposed gelation index (time to reach $G$ '$G$ " crossover) to evaluate temperature dependence of the crosslinking kinetics for the tested silane-grafted polyethylenes is not applicable. This is because $G$ '-G' crossover for NOK sample has already passed whereas time to reach this point for OK sample is extremely small (in orders of several seconds). In order to overcome this difficulty, the time at which the crosslinking speed is the heights (i.e. the time at which the maximum change in the complex viscosity takes place) was used for this purpose. This critical crosslinking reaction time was determined from the time dependent complex viscosity measured for both tested samples, at three different temperatures $\left(205^{\circ} \mathrm{C}, 215^{\circ} \mathrm{C}, 225^{\circ} \mathrm{C}\right)$ in air atmosphere where the crosslinking reaction is more intensive in comparison with the nitrogen atmosphere (see Figure 6).
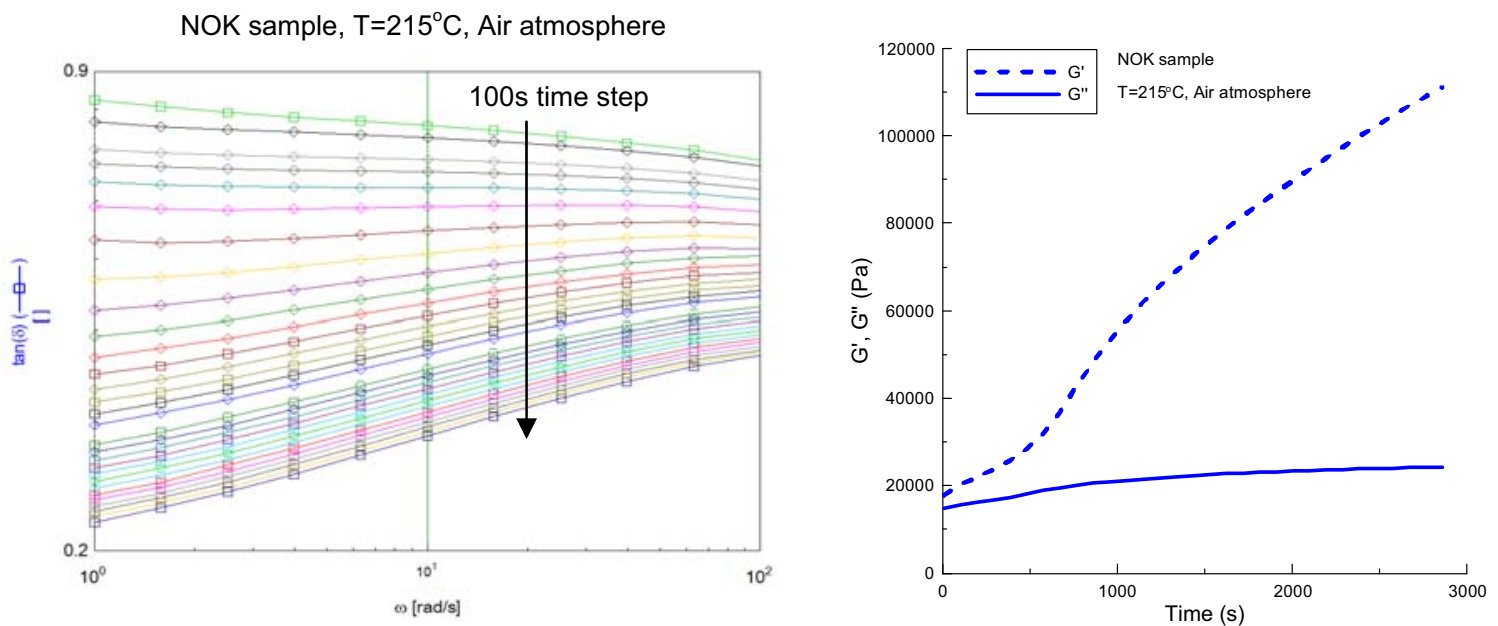

FIGURE 4. Rheological measurements for NOK sample at $215^{\circ} \mathrm{C}$ in air atmosphere.

Left: Plot of $\tan \delta$ versus the frequency for different crosslinking times (increased crosslinking time leads to the $\tan \delta$ decreases). Right: Loss and storage moduli versus the time.
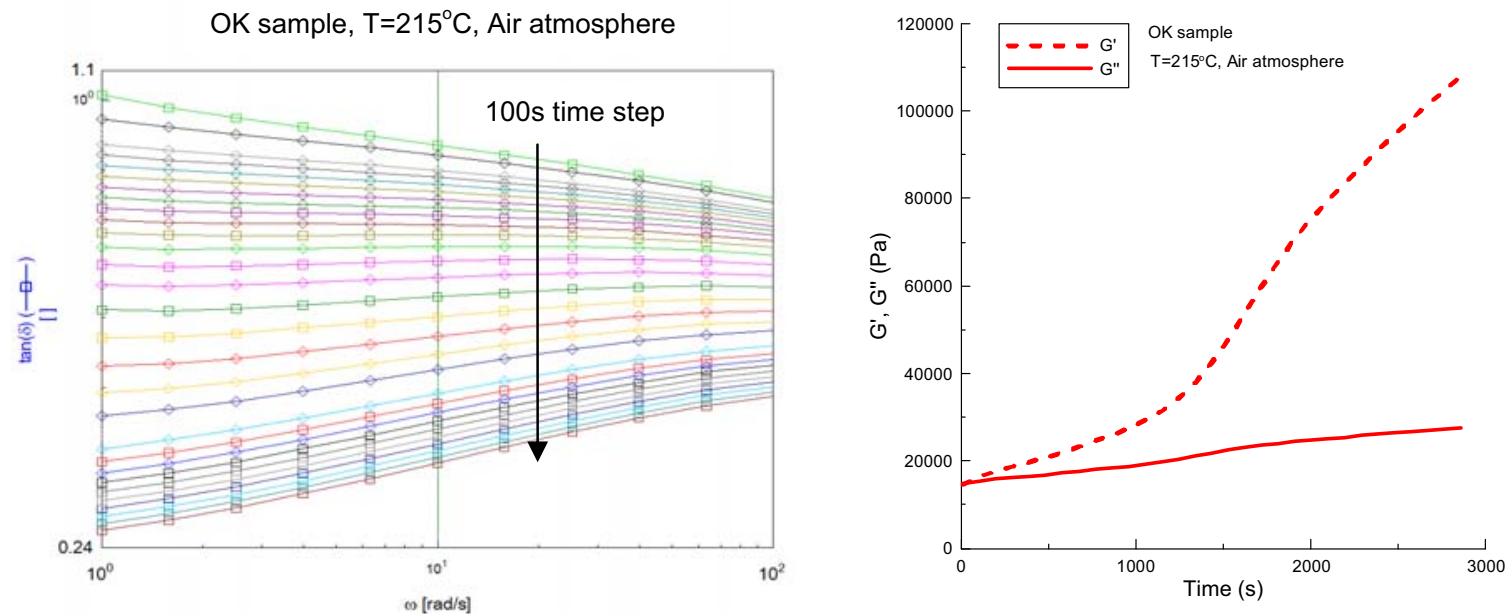

FIGURE 5. Rheological measurements for OK sample at $215^{\circ} \mathrm{C}$ in air atmosphere. Left: Plot of $\tan \delta$ versus the frequency for different crosslinking times (increased crosslinking time leads to the $\tan \delta$ decreases). Right: Loss and storage moduli versus the time. 

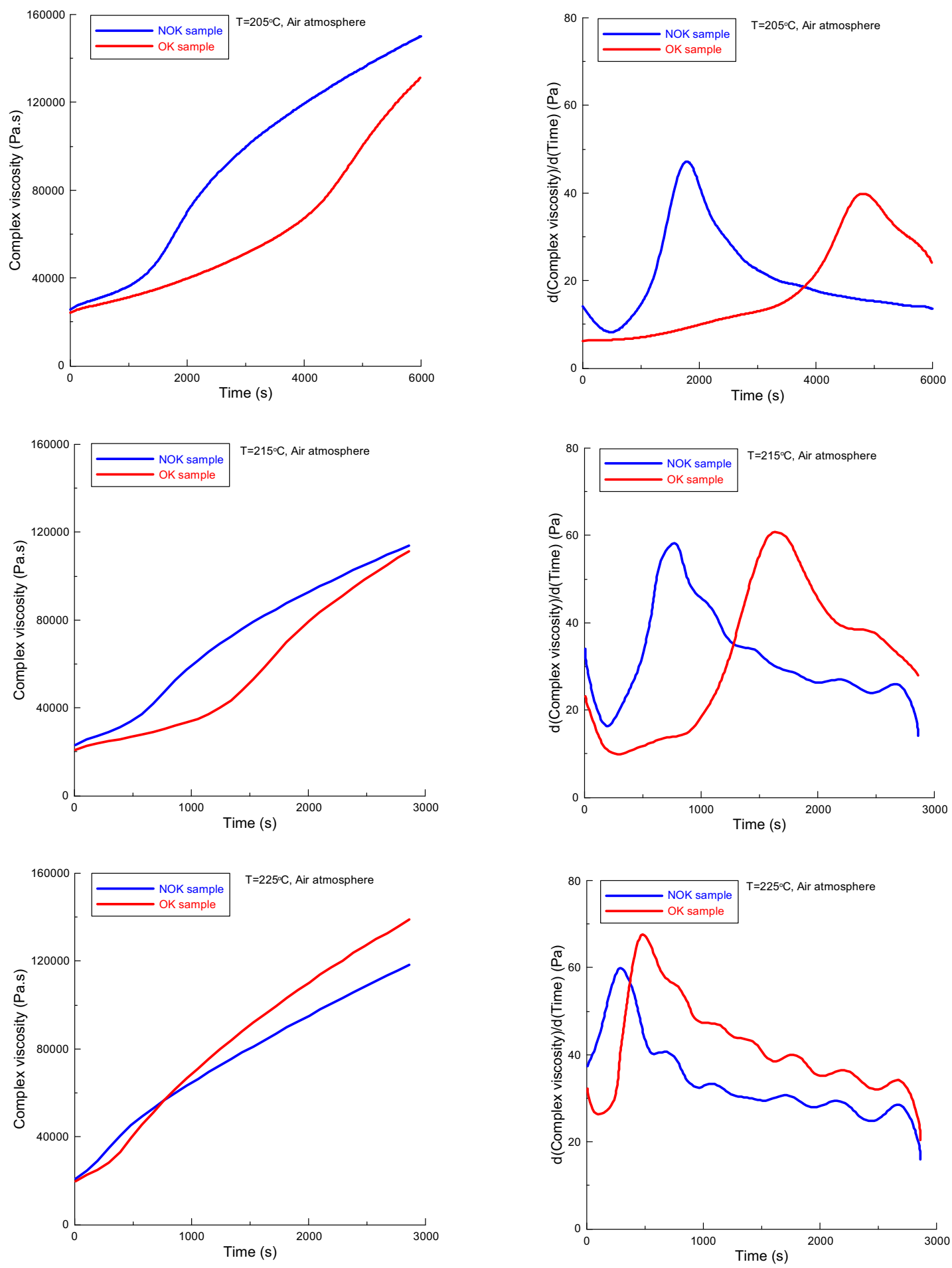

FIGURE 6. Rheological measurements for both tested samples at $205^{\circ} \mathrm{C}$ (top), $215^{\circ} \mathrm{C}$ (middle) and $225^{\circ} \mathrm{C}$ (bottom) in air atmosphere. Left: Complex viscosity versus the time.

Right: $\mathrm{d}($ Complex viscosity)/d(Time) versus the time. 
Interestingly, temperature dependence of the critical time at which the crosslinking speed is the highest shows an Arrhenius-type behaviour (see Figure 7), which has practical consequences with respect to evaluation/optimization of silane-grafted polyethylenes and processing conditions.

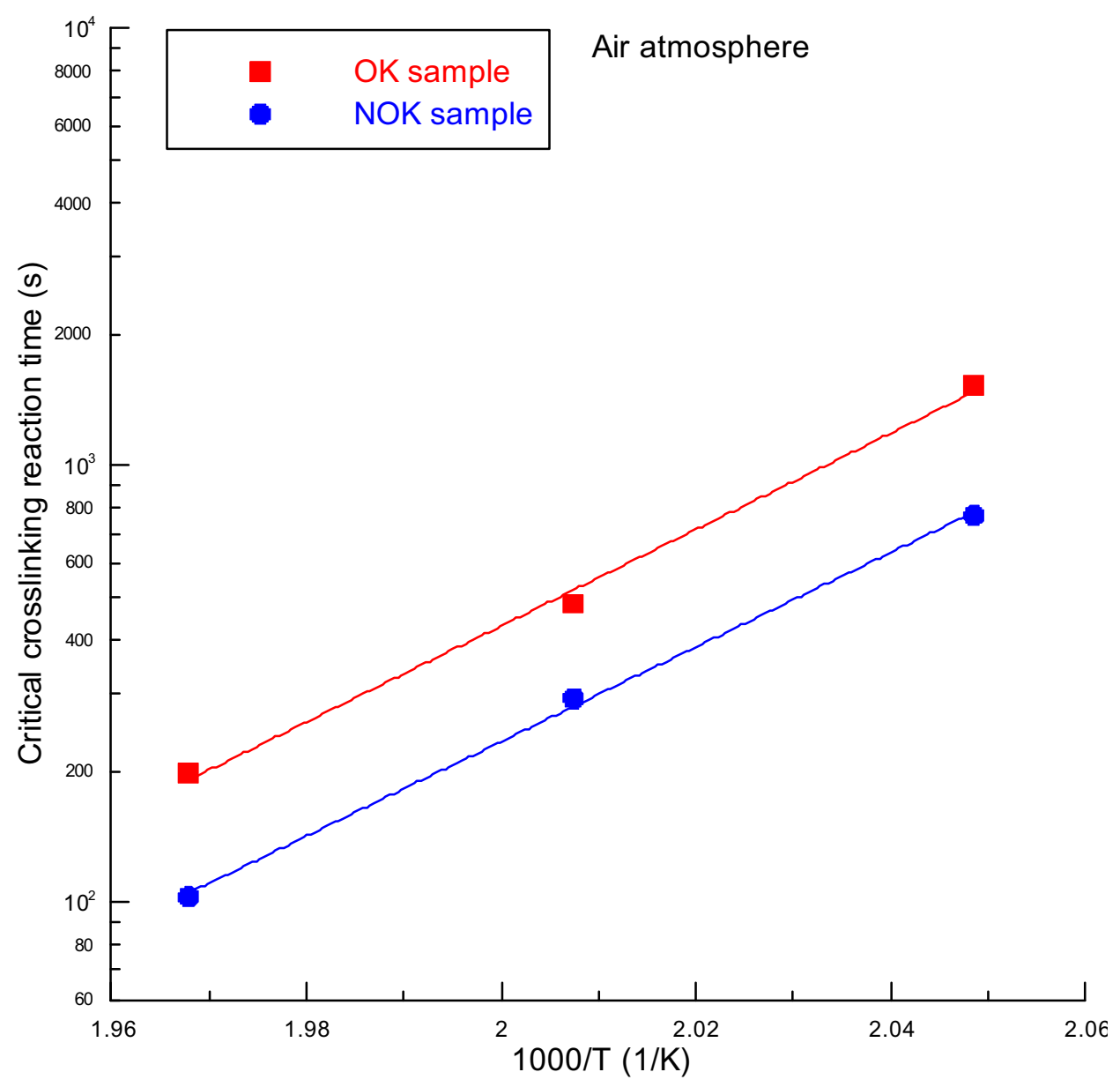

FIGURE 7. Critical crosslinking reaction time versus the temperature for both tested samples in air atmosphere.

\section{CONCLUSIONS}

The crosslinking behaviour of two silane-grafted polyethylenes was investigated as a function of time and temperature by using rheological measurements in the dynamicmechanical mode. It has been found that inhomogeneous character of the crosslinking reaction in both tested samples takes place which limits precise determination of physically well-defined gel point state and thus $G^{\prime}-G^{\prime}$ ' crossover point method was used to distinct initial crosslinking state of both samples. It was found that the sample which has already passed $G^{\prime}-G^{\prime \prime}$ crossover point and having very short critical crosslinking reaction time has very high tendency to create small gels during production of hot water pipes. It has also been revealed that the temperature dependence of the critical time at which the crosslinking speed is the highest 
(determined from the complex viscosity plotted versus the time) shows an Arrheniustype behaviour.

\section{ACKNOWLEDGMENTS}

The authors wish to acknowledge Operational Program Research and Development for Innovations co-funded by the European Regional Development Fund (ERDF) and national budget of Czech Republic, within the framework of project Centre of Polymer Systems (reg. number: CZ.1.05/2.1.00/03.0111) for the financial support.

\section{REFERENCES}

1. J. Moeshedian and P. M. Hoseinpour, Iran. Polym. J. (English Edition) 18, 103-128 (2009).

2. H. G. Scott, U.S. Patent No. 3,646,155 (1972).

3. S. Ultsch and H. G. Fritz, Plast. Rubber. Process. Appl. 13, 81-91 (1990).

4. $\quad$ M. Mehrabzade, J. Morshedian, J. Barzin, Iran. J. Polym. Sci. Technol. 1, 3-10 (1998).

5. $\quad$ Y.-T. Shieh and C.-M Liu, J. Appl. Polym. Sci. 74, 3404-3411 (1999).

6. Y.-T. Shieh, J.-S. Liau and T.-K. Chen, J. Appl. Polym. Sci. 81, 186-196 (2001).

7. M. Bengtsson, P. Gatenholm and K. Oksman, Composites Sci. Technol. 65, 1468-1479 (2005).

8. H.-C. Kuan, J.-F. Kuan, C.-C. M. Ma, J.-M. Huang, J. Appl. Polym. Sci. 96, 2383-2391 (2005).

9. K. Sirisinha, M. Boonkongkaew and S. Kositchaiyong, Polym. Test. 29, 958-965 (2010).

10. C. M. Clemons, R. C. Sabo and K. C. Hirth, J. Appl. Polym. Sci. 120, 2292-2303 (2011).

11. A. Sharif-Pakdaman, J. Morshedian and Y. Jahani, J. Appl. Polym. Sci. 125, E305-E313 (2012).

12. H. H. Winter, Polym. Eng. Sci. 27, 1698-1702 (1987).

13. F. Wolff, C. Kugler and H. Münstedt, Rheol. Acta 50, 917-924 (2011).

14. J. C. Scanlan and H. H. Winter, Macromolecules 24, 47-54 (1991).

15. F. Wolff, C. Kugler, H. Münstedt, Rheol. Acta 51, 71-80 (2012).

16. C. Y. M. Tung and P. J. Dynes, J. Appl. Polym. Sci. 27, 569-574 (1982).

17. ASTM D 4473-08, 2008 